\title{
Cardiac surgery outcomes in patients with coronavirus disease 2019 (COVID-19): A case-series report
}

Khalil Fattouch, MD, PhD, ${ }^{\text {a,b }}$ Salvatore Corrao, MD, ${ }^{\mathrm{c}, \mathrm{d}}$ Ettore Augugliaro, MD, ${ }^{\mathrm{a}}$ Alberto Minacapelli, MD, ${ }^{\mathrm{a}}$ Angela Nogara, MD, ${ }^{a}$ Giulia Zambelli, MD, ${ }^{a}$ Christiano Argano, MD, $\mathrm{PhD},{ }^{c}$ and Marco Moscarelli, MD, $\mathrm{PhD}^{\mathrm{a}, \mathrm{b}}$

\section{ABSTRACT}

Objective: The impact of coronavirus disease 2019 (COVID-19) on the postoperative course of patients after cardiac surgery is unknown. We experienced a major severe acute respiratory syndrome coronavirus 2 (SARS-CoV-2) outbreak in our cardiac surgery unit, with several patients who tested positive early after surgery. Here we describe the characteristics, postoperative course, and laboratory findings of these patients, along with the fate of the health care workers. We also discuss how we reorganize and reallocate hospital resources to resume the surgical activity without further positive patients.

Methods: After diagnosis of the first symptomatic patient, surgery was suspended. Nasopharyngeal swabs were performed in all patients and health care workers. Patients who were positive for SARS-CoV-2 were isolated and monitored throughout the in-hospital stay and followed up after discharged until death or clinical recovery.

Results: Twenty patients were found to be positive for SARS-CoV-2 sometime after cardiac surgery (mean age $69 \pm 10.4$ years; median European System for Cardiac Operative Risk Evaluation II score 3 [interquartile range, 5.1]); the median time from surgery to diagnosis was 15 days (interquartile range, 11). Among the patients, 18 had undergone cardiac surgery and 2 of them transcatheter aortic valve replacement. Overall mortality was $15 \%$. Specific COVID-19-related symptoms were identified in 7 patients $(35 \%)$. Among the 12 health care workers infected, 1 developed a bilateral mild-grade interstitial pneumonia.

Conclusions: COVID-19 infection after cardiac surgery, regardless the time of the onset, is a serious condition. The systemic inflammatory state that follows extracorporeal circulation may mask the typical COVID-19 laboratory findings, making the diagnosis more difficult. A strict reorganization of the hospital resources is necessary to safely resume the cardiac surgical activity. (J Thorac Cardiovasc Surg 2022;163:1085-92)

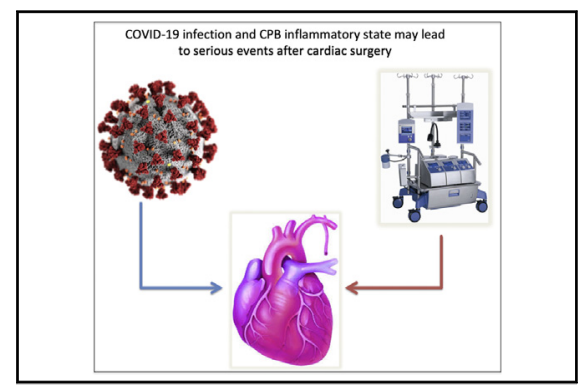

COVID-19 and CPB inflammatory state may lead to serious events in cardiac surgery.

CENTRAL MESSAGE

COVID-19 infection resulted in 3 deaths in 20 patients. COVID-19 diagnosis may be challenging in a cardiac surgery context.

\section{PERSPECTIVE}

We experienced a major SARS-CoV-2 outbreak, with 20 patients and 12 health care workers infected. In all patients, COVID-19 was diagnosed sometime after cardiac surgery. Three patients died. No other major complications were observed. COVID-19 diagnosis after cardiac surgery might be difficult due to the systemic inflammatory state that follows CPB.

See Commentaries on pages 1093 and 1095.
The pandemic infection caused by the novel coronavirus 2 (severe acute respiratory syndrome coronavirus 2 [SARS-CoV-2]/coronavirus disease 2019 [COVID-19]) has dramatically affected cardiac surgery worldwide. ${ }^{1}$

\footnotetext{
From ${ }^{\text {a Department }}$ of Cardiovascular Surgery, GVM Care \& Research, Maria Eleonora Hospital, Palermo; ' $\mathrm{GVM}$ Care \& Research, Maria Cecilia Hospital, Cotignola (RA); ${ }^{\mathrm{c}}$ Department of Internal Medicine, National Relevance and High Specialization Hospital Trust ARNAS Civico, Di Cristina, Benfratelli, Palermo; and ${ }^{\mathrm{d}}$ Dipartimento di Promozione della Salute, Materno Infantile, Medicina Interna e Specialistica di Eccellenza “G. D'Alessandro," PROMISE, University of Palermo School of Medicine, Palermo, Italy.

Received for publication May 19, 2020; revisions received Sept 24, 2020; accepted for publication Sept 28, 2020; available ahead of print Oct 22, 2020.

Address for reprints: Marco Moscarelli, MD, PhD, GVM Care \& Research, Maria Eleonora Hospital, Viale della Regione Siciliana Nord Ovest, 1571, 90135 Palermo (PA), Italy (E-mail: m.moscarelli@imperial.ac.uk).

$0022-5223 / \$ 36.00$

Copyright (c) 2020 by The American Association for Thoracic Surgery https://doi.org/10.1016/j.jtcvs.2020.09.138
}

Many cardiac surgery centers were converted to COVID19 units. $^{2}$ Consequentially, a significant reduction of surgical cases has been reported, with a potential negative impact to the community. ${ }^{3}$ COVID-19 may be a lethal condition due to respiratory tract involvement and might represent a major contraindication to surgery unless emergent serious conditions (ie, acute aortic dissection) arise. ${ }^{4}$

Few data are available on the effect of COVID-19 in patients undergoing cardiac surgery procedures. ${ }^{5}$ There are also no firm recommendations available to guide decision

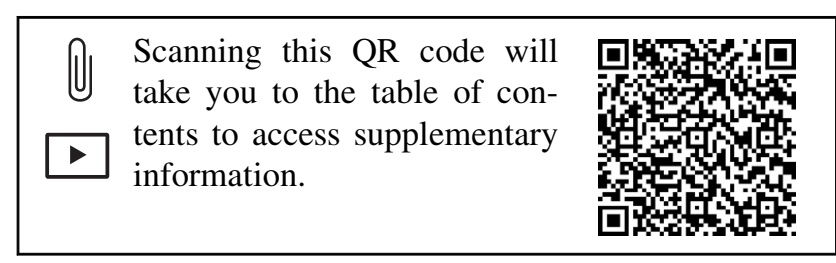




\section{Abbreviations and Acronyms \\ COVID-19= coronavirus disease 2019 \\ CT $=$ computed tomography \\ SARS-CoV-2 $=$ severe acute respiratory syndrome coronavirus 2 \\ TAVR $=$ transcatheter aortic valve replacement}

making for patients requiring cardiac surgery during the pandemic.

While assuring the treatment of urgent cases, we experienced a SARS-CoV-2 outbreak in our cardiovascular division (GVM Care \& Research, Maria Eleonora Hospital, Palermo, Italy) during the apex of the pandemic in Italy, with 20 patients found positive with SARS-CoV-2 sometime after surgery. Twelve health care workers were also affected.

The aim of this paper is to describe the baseline characteristics, postoperative course, and laboratory findings of these patients. Measures adopted to contain the spread of the new coronavirus are also discussed, along with the fate of the health-care workers. In addition, we present the way we reorganized and reallocated hospital resources to resume surgical activity.

\section{METHODS}

\section{Hospital Scenario and Population}

Maria Eleonora Hospital, GVM Care \& Research, is a tertiary cardiovascular hospital located in Palermo, Italy. Early after the start of the COVID-19 outbreak in Italy, it was designated by local authority as one of the main "COVID-19 free" hubs for urgent and emergent cardiovascular procedures in the district of Palermo. At the climax of the Italian outbreak in early April, we were performing 2 to 3 major cardiac operations each day. Patients were referred to us and accepted for surgery if affected by nondeferrable cardiac conditions such as acute coronary syndromes and symptomatic coronary artery disease with unfavorable anatomy and/or not amenable to percutaneous coronary intervention (ie, left main stem, proximal left anterior descending artery); symptomatic aortic valve stenosis or regurgitation or symptomatic mitral valve regurgitation despite optimized medical therapy; disease of the ascending aorta (symptomatic aortic aneurysm or dissection); and other short-term life-threatening cardiac disorders (ie, cardiac valves endocarditis).

Before hospital admission, patients were screened for COVID-19 according to the regional health care system recommendations, which included core temperature $>37^{\circ} \mathrm{C}$, cough and/or dyspnea without a clear alternative cause, recent domestic/international travel, and contact with a known or suspected patient with COVID-19. Nasopharyngeal swabs were not carried out, nor did we use a fast kit to detect immunoglobulin $\mathrm{M}$ and immunoglobulin $\mathrm{G}$ in the blood of both patients and health care workers during the triage phase. From early March onward, personal protective equipment was available and worn by any health care workers. Moreover, in-hospital visits by relatives were forbidden to all patients.

\section{Statistical Analysis, Follow-up, Ethics}

Before descriptive analysis, data were checked for normality distribution with the Shapiro test. Continuous normal distributed variables are presented as mean \pm standard deviation, alternatively as median and interquartile range. Categorical variables were presented as percentages. Intergroup comparisons were performed with 2-tailed $t$ test or Wilcoxon rank-sum test according to distribution of data. R 2.13.2 software (R Development Core Team, Vienna, Austria) was used for descriptive statistical analysis.

Follow-up was obtained by directly contacting the patients themselves or the COVID-19 units where patients were transferred or the patients themselves. All patients were contacted by phone and they verbally expressed the will to participate to the study. The study protocol was reviewed and approved by our internal institutional review board, and the requirement for patient consent was waived.

\section{RESULTS}

There were 55 inpatients at the time of the COVID-19 outbreak in our hospital. Among them, 20 patients were found positive for SARV-CoV-2 sometime after surgery (mean age $71 \pm 11.5$ years; of them, 11 were female); 18 had undergone cardiac surgery and 2 of them transcatheter aortic valve replacement (TAVR); all patients were found positive, except one, while in-hospital, in the cardiac, or rehab ward. Table 1 reports the surgical patients' baseline characteristics and Table 2 the operative details. All individuals who tested positive for the new coronavirus were operated between March 9, 2020, and April 6, 2020, but one had their operation on January 23, 2020.

\section{The First Patient Symptomatic for COVID-19}

The first patient with symptoms of COVID-19 was a 71year-old woman who underwent double-valve replacement (aortic and mitral valve) and coronary artery bypass grafting on March 10, 2020. Her early postoperative course was uneventful. She was transferred to the rehabilitation ward, where she started spiking a temperature (above $37.5^{\circ} \mathrm{C}$ ) for 2 days continuously. Computed tomography (CT) scan of the chest revealed suspicious findings for COVID-19 (Figure $1, A$ and $B$ ). Nasopharyngeal swab, performed 27 days after the index surgery, confirmed the diagnosis (COVID-19 test/real-time reverse transcription polymerase chain reaction). She was promptly isolated and transferred over to the Partinico COVID unit (Italy) in stable respiratory condition (saturation $98 \%-100 \%$ in room air). However, after 2 days, she experienced a severe and rapid deterioration of respiratory conditions that required endotracheal intubation and invasive mechanical ventilation. She was weaned from invasive ventilation 10 days later. She developed sternal wound dehiscence and eventually died on March 8, 2020, due to unrecognized sternal bleeding while in isolation.

\section{Quarantine Policy}

Immediately after detection of the first positive patient, cardiac surgery activity was suspended. All patients and health care workers were tested for SARS-CoV-2. Preoperative negative patients were diverted to other hospitals. All 
TABLE 1. Baseline patient characteristics

\begin{tabular}{|c|c|}
\hline $\mathbf{N}=\mathbf{1 8}$ & \\
\hline Age, $y$, mean $\pm S D$ & $69 \pm 10.4$ \\
\hline Body mass index, $\mathrm{kg} / \mathrm{m}^{2}$, mean $\pm \mathrm{SD}$ & $26.5 \pm 4.5$ \\
\hline Male sex, n (\%) & $9(50)$ \\
\hline Systemic hypertension, $\mathrm{n}(\%)$ & $13(72)$ \\
\hline Non-insulin-dependent diabetes mellitus, $\mathrm{n}(\%)$ & $3(16.6)$ \\
\hline Insulin-dependent diabetes mellitus, $\mathrm{n}(\%)$ & $1(5.5)$ \\
\hline Chronic obstructive pulmonary disease, $\mathrm{n}(\%)$ & $2(11.1)$ \\
\hline Current smoking, $\mathrm{n}(\%)$ & $2(11.1)$ \\
\hline Creatinine, mg/dL (IQR) & $1.3(0.95)$ \\
\hline eGFR (IQR) & $33.4(61.5)$ \\
\hline $\begin{array}{l}\text { Pulmonary hypertension, } \mathrm{n}(\%) \\
31-55 \mathrm{~mm} \mathrm{Hg} \\
>55 \mathrm{~mm} \mathrm{Hg}\end{array}$ & $\begin{array}{l}6(33.3) \\
1(5.5)\end{array}$ \\
\hline Left ventricle ejection fraction, $\% \pm \mathrm{SD}$ & $51.5 \pm 11.2$ \\
\hline Recent myocardial infarction, $\mathrm{n}(\%)$ & $2(11.1)$ \\
\hline $\begin{array}{l}\text { CCS, n }(\%) \\
\quad 3 \\
4\end{array}$ & $\begin{array}{l}3(16.6) \\
3(16.6)\end{array}$ \\
\hline $\begin{array}{l}\text { NYHA, n (\%) } \\
2 \\
3\end{array}$ & $\begin{array}{r}7(38.8) \\
11(61.1)\end{array}$ \\
\hline Aortic valve stenosis, n (\%) & $7(38.8)$ \\
\hline Aortic valve regurgitation, $\mathrm{n}(\%)$ & $3(16.6)$ \\
\hline Mitral valve regurgitation, $\mathrm{n}(\%)$ & $4(22.2)$ \\
\hline Ascending aorta aneurysm, n (\%) & $5(27.7)$ \\
\hline ACS NSTEMI & $5(27.7)$ \\
\hline Previous PCI, n (\%) & $4(22.2)$ \\
\hline Active endocarditis, n (\%) & $1(5.5)$ \\
\hline EuroSCORE II, median (IQR) & $3(5.1)$ \\
\hline
\end{tabular}

Data are presented as mean \pm standard deviation $(\mathrm{SD})$ or median and interquartile range (IQR) or number and frequency (\%).eGFR, Estimated glomerular filtration rate (Cockcroft-Gault); CCS, Canadian Class Society; NYHA, New York Heart Association; ACS, acute coronary syndrome; NSTEMI, non-ST elevation myocardial infarction; $P C I$, percutaneous coronary intervention; EuroSCORE, European System for Cardiac Operative Risk Evaluation.

the positive postoperative patients were transferred over to dedicated COVID-19 units when hemodynamically and respiratory stable.

All health care workers waited the results of the nasopharyngeal test before leaving the hospital premises. Workers who were found to be negative were allowed to go home, whereas those who were positive were transferred over COVID-19 quarantine centers.

\section{The Rest of the Population Positive for SARS-CoV-2}

One patient with severe left ventricle dysfunction who underwent aortic valve and ascending aorta replacement
TABLE 2. Operative details and postoperative outcome of patients with COVID-19

\begin{tabular}{|c|c|}
\hline $\mathbf{N}=\mathbf{1 8}$ & \\
\hline \multicolumn{2}{|l|}{ Operation type } \\
\hline Aortic valve replacement, $\mathrm{n}$ & 6 \\
\hline Mitral valve replacement, $\mathrm{n}$ & 2 \\
\hline Mitral valve repair, $\mathrm{n}$ & 1 \\
\hline Coronary artery bypass grafting, $n$ & 4 \\
\hline $\begin{array}{l}\text { Aortic valve replacement, mitral valve repair and } \\
\text { coronary artery bypass grafting, } n\end{array}$ & 1 \\
\hline $\begin{array}{l}\text { Aortic valve replacement and coronary artery bypass } \\
\text { grafting, } \mathrm{n}\end{array}$ & 1 \\
\hline $\begin{array}{l}\text { Aortic valve replacement and ascending aorta } \\
\text { replacement, } \mathrm{n}\end{array}$ & 2 \\
\hline $\begin{array}{l}\text { Aortic valve replacement, ascending aorta } \\
\text { replacement and coronary artery bypass grafting }\end{array}$ & 1 \\
\hline Cardiopulmonary bypass time, min, median (IQR) & $75.5(26.7)$ \\
\hline Crossclamp time, min, median (IQR) & $50.5(11)$ \\
\hline \multicolumn{2}{|l|}{ Postoperative results } \\
\hline Overall mortality, $\mathrm{n}(\%)$ & $3(16.6)$ \\
\hline Mechanical ventilation time, min, median (IQR) & $7(7)$ \\
\hline Postoperative intubation time $>24 \mathrm{~h}, \mathrm{n}(\%)$ & $1(5.5)$ \\
\hline Respiratory failure $\left(\mathrm{Po}_{2} / \mathrm{FIO}_{2}<200\right)$ & $2(11.1)$ \\
\hline Acute kidney injury $1, \mathrm{n}(\%)$ & $8(44.4)$ \\
\hline Acute kidney injury $2, \mathrm{n}(\%)$ & $2(11.1)$ \\
\hline Acute kidney injury 3, n (\%) & $3(16.6)$ \\
\hline Peak creatinine, mg/dL, median (IQR) & $1.5(1.05)$ \\
\hline Use of inotropes/vasopressor, $\mathrm{n}(\%)$ & $8(44.4)$ \\
\hline Number of packed red cells, median (IQR) & $1(3)$ \\
\hline Reopening for bleeding, $\mathrm{n}(\%)$ & $1(5.5)$ \\
\hline De novo atrial fibrillation, $\mathrm{n}(\%)$ & $11(67.2)$ \\
\hline Left ventricle ejection fraction, $\% \pm \mathrm{SD}$ & $47.7 \pm 19.7$ \\
\hline Intensive care unit length of stay, $d$, median (IQR) & $2(1.2)$ \\
\hline In-hospital length of stay, d, median (IQR) & $18(14)$ \\
\hline
\end{tabular}

Data are presented as mean \pm standard deviation (SD) or median and interquartile range (IQR) or number and frequency (\%). Acute kidney injury accordingly to RIFLE (Risk, Injury, Failure, Loss of kidney function, and End-stage kidney disease) criteria. $\mathrm{PO}_{2}$, Oxygen tension; $\mathrm{FIO}_{2}$, inspired oxygen fraction.

died 2 days after surgery as the result of acute kidney dysfunction followed by multiorgan failure. He was diagnosed with COVID-19 the day after surgery. One patient died 2 days after having been transferred over to a dedicated COVID-19 unit as the result of severe respiratory and renal failure. He was a severely critically ill patient with previous kidney transplantation and end-stage renal disease who underwent emergent aortic valve replacement after having been diagnosed with bacterial aortic valve endocarditis.

The rest of the postoperative complications are described in Table 2. Median time from surgery to COVID-19 diagnosis was 15 days (interquartile range, 11), minimum 2 and maximum 76 days after surgery (Table 3 ). Eighteen patients were found positive before 30 days from surgery, as well as one 33 days and another one 76 days after surgery. Seven patients $(38.8 \%)$ showed typical symptoms that 

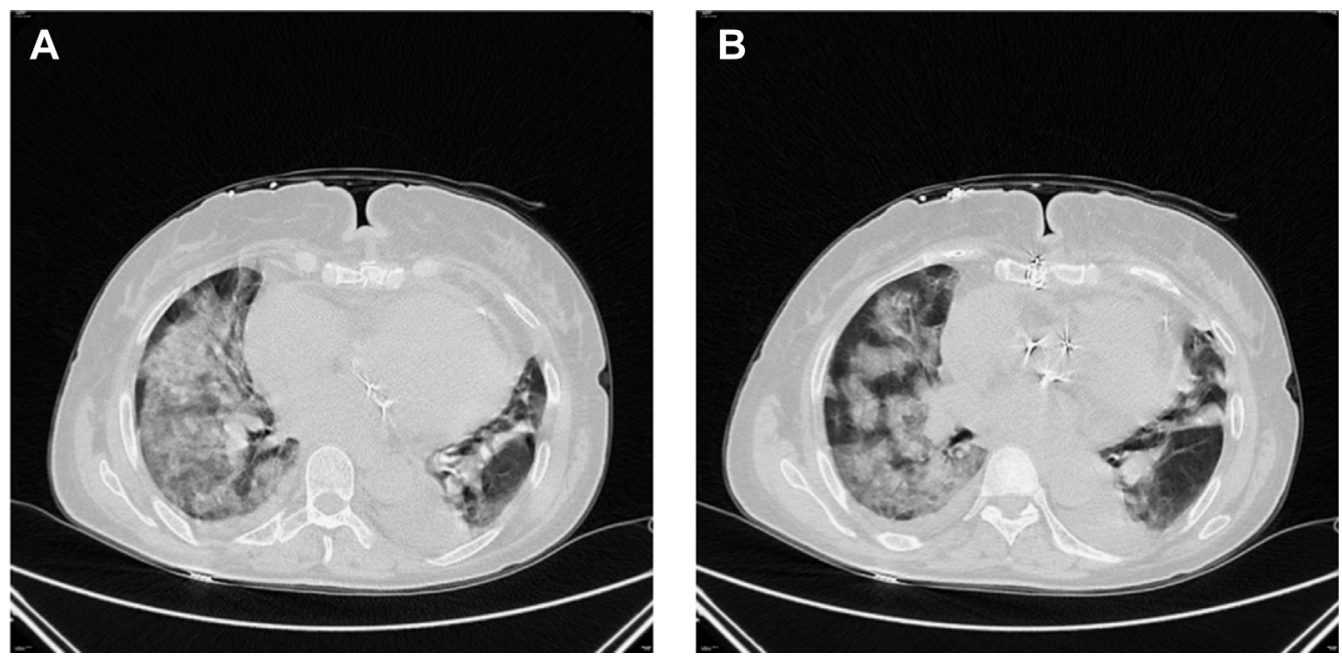

FIGURE 1. A and B, Computed tomography scan of the chest of the first patient found positive for severe acute respiratory syndrome coronavirus 2 after median sternotomy and double-valve replacement and coronary artery bypass grafting.

could be associated with COVID-19 (Table 3). There were no complications that could be related to the potential hypercoagulopathy state due to COVID-19 infection (such as deep venous thrombosis). No other major complications were observed. The postoperative course of the patients undergoing TAVR was uneventful.

\section{Laboratory Findings}

Table 4 reports relevant available laboratory findings from baseline to the day of COVID-19 diagnosis. There was a trend toward a reduction of lymphocyte count, whereas neutrophils were overexpressed from early after surgery (Figure 2). The antithrombin III value was toward the lower limit (mean $80.8 \pm 22.2 \%$ ), whereas D-dimer

TABLE 3. COVID-19 diagnosis and symptoms

\begin{tabular}{|c|c|}
\hline $\mathbf{N}=\mathbf{1 8}$ & \\
\hline $\begin{array}{l}\text { Days from index surgery to diagnosis, median } \\
\text { (IQR) }\end{array}$ & $\begin{array}{c}15(11) \\
\text { range, } 2-76 \mathrm{~d}\end{array}$ \\
\hline $\begin{array}{l}\text { Days from index surgery to symptoms, median } \\
\text { (IQR) }\end{array}$ & $\begin{array}{c}17(13) \\
\text { range, } 4-29\end{array}$ \\
\hline No symptoms, $\mathrm{n}(\%)$ & $11(61.1)$ \\
\hline Fever $>37.5^{\circ} \mathrm{C}, \mathrm{n}(\%)^{*}$ & $6(33.3)$ \\
\hline Dry cough, $\mathrm{n}(\%)$ & $2(11.1)$ \\
\hline Dyspnea, n (\%) & $3(16.6)$ \\
\hline Need for high-flow oxygen therapy, n (\%) & $4(22.2)$ \\
\hline $\begin{array}{l}\text { Readmission to intensive care unit for } \\
\text { mechanical ventilation, } \mathrm{n}(\%)\end{array}$ & $1(5.5)$ \\
\hline CT chest performed, $n(\%)$ & $3(16.6)$ \\
\hline
\end{tabular}

and fibrinogen were significantly elevated at the time of the COVID-19 diagnosis.

\section{Follow-up}

The 17 survivors (15 surgical patients and the 2 patients who received TAVR) were followed up on a regular basis by contacting the COVID-19 centers where they were transferred or speaking to them by phone if they had been discharged to home. Mean follow-up was $62.8 \pm 17.8$ days, $100 \%$ completed. Nine patients of the 17 survivors were transferred to quarantine hotels since they did not need active medical treatment.

Eight patients were admitted to the COVID-19 Department of Internal Medicine of Civico Hospital (Palermo, Italy) for further close observation. On admission, all patients underwent $\mathrm{CT}$ of the chest, which showed minimal interstitial pneumonia appearance. Laboratory findings showed elevated C-reactive protein and D-dimer levels in 7 subjects, whereas mild lymphocytopenia was present in 4 . No patients took antiretroviral drugs. Six patients started treatment with hydroxychloroquine and azithromycin. One patient took only azithromycin because he was treated with amiodarone. One patient took only methylprednisolone because of prolonged QT. At the moment of writing this manuscript, all patients fully recovered from SARS-CoV-2 infection, as determined by negative nasopharyngeal swab.

\section{The Fate of the Health Care Workers}

Twelve hospital care workers tested positive for SARSCoV-2 (1 physician, 6 nurses, 2 physiotherapists, 2 cooks, and 1 cleaner). Three of them were moderately symptomatic for cough and mild dyspnea. One of them developed a bilateral mild-grade interstitial pneumonia. At the time 
TABLE 4. Laboratory findings

\begin{tabular}{|c|c|c|c|c|c|c|}
\hline & Baseline & Day 2 & Day 4 & Day 6 & $24 / 48$ h before NP swab & Swab+ \\
\hline $\mathrm{WBC}, \times 10^{3} / \mathrm{mm}^{3}$ & $7.5 \pm 1.5$ & $13.5 \pm 3.9$ & $10.2 \pm 1.4$ & $11 \pm 2.4$ & $9.1 \pm 3.5$ & $6.9 \pm 2.8$ \\
\hline Lymphocytes & $2.1 \pm 0.8$ & $2.5 \pm 3$ & $1.7 \pm 0.8$ & $1.7 \pm 0.8$ & $1.5 \pm 0.8$ & $1.3 \pm 0.8$ \\
\hline $\mathrm{L} \%$ & $28.3 \pm 9.1$ & $11.1 \pm 6.5$ & $16.9 \pm 7.4$ & $16.1 \pm 8.2$ & $18.9 \pm 7.8$ & $20.2 \pm 8.8$ \\
\hline Neutrophils & $4.3 \pm 1$ & $15.2 \pm 17$ & $7.4 \pm 1.2$ & $7.9 \pm 2.1$ & $6.6 \pm 3.7$ & $4.9 \pm 2.5$ \\
\hline $\mathrm{N} \%$ & $60.3 \pm 10.3$ & $76.3 \pm 16.8$ & $72.6 \pm 9.2$ & $71.6 \pm 11$ & $70.8 \pm 10.9$ & $69.9 \pm 11.2$ \\
\hline AT III, \% & & & & $74.3 \pm 6.7$ & $71.5 \pm 8.7$ & $80.8 \pm 22.2$ \\
\hline Fibrinogen, mg/dL & & & & $568.4 \pm 156.9$ & & $559.4 \pm 136.4$ \\
\hline D-dimer, $\mu \mathrm{g} / \mathrm{mL}$ & & & & & & $1100.1 \pm 581.6$ \\
\hline Procalcitonin, $\mu \mathrm{g} / \mathrm{L}$ & & & & & & $0.1 \pm 0.09$ \\
\hline $\mathrm{CRP}, \mathrm{mg} / \mathrm{dL}$ & & & & & & $60.6 \pm 51.9$ \\
\hline
\end{tabular}

WBC: "baseline" vs "swab+", $P=.21$; lymphocytes: "baseline" vs "swab+", $P<.01$; neutrophils: "baseline" vs "swab+", $P=.81$. NP, Nasopharyngeal; $W B C$, white cell count; $A T$ III, antithrombin III; CRP, C-reactive protein.

of writing this manuscript, all the health care workers recovered from COVID-19.

\section{Measures of Screening and Hospital Policy}

Strict measures of screening and drastic changes of hospital policy were introduced and described in Figure E1 (gray area and bubble principle). Surgical activity resumed on July 1, 2020; 108 elective/urgent cardiac surgery cases were performed (from July to August 2020), including 2 acute mitral valve endocarditis.

Patients' characteristics, operation type, and outcome are described in Table E1. In 3 patients with slow respiratory weaning from mechanical ventilation, CT scan of the chest was performed with no radiologic evidence for COVID-19; no patients nor health care workers were found positive for SARS-Cov-2 after surgery was resumed.

\section{DISCUSSION}

In this paper, we describe the case of a COVID-19 outbreak that occurred in the setting of a cardiac surgery unit. Patients were at moderate-to-high risk for surgery, affected by nondeferrable cardiac conditions. Three patients died; however, most of the patients remained asymptomatic or pauci-symptomatic. The observed mortality rate was greater what would be expected in similar patients.

Few data are available on the effect of the novel coronavirus infection in patients who recently had cardiac surgery procedures. Rescigno and colleagues ${ }^{5}$ described a case of a 63-year-old patient referred for coronary artery bypass grafting who died some days later after surgery and the presumed cause of death was severe postoperative COVID-19 pneumonia. Fukuhara and colleagues ${ }^{4}$ presented a patient with acute type $\mathrm{A}$ aortic dissection later diagnosed with COVID-19 who died after surgery. In these 2 cases, realtime reverse transcription polymerase chain reaction tests were not performed preoperatively.

The need for prolonged mechanical ventilation support may cause sternal wound dehiscence after cardiac surgery. In our series, 1 patient died as a result of a serious bleeding from the dehisced sternal wound, while in isolation.

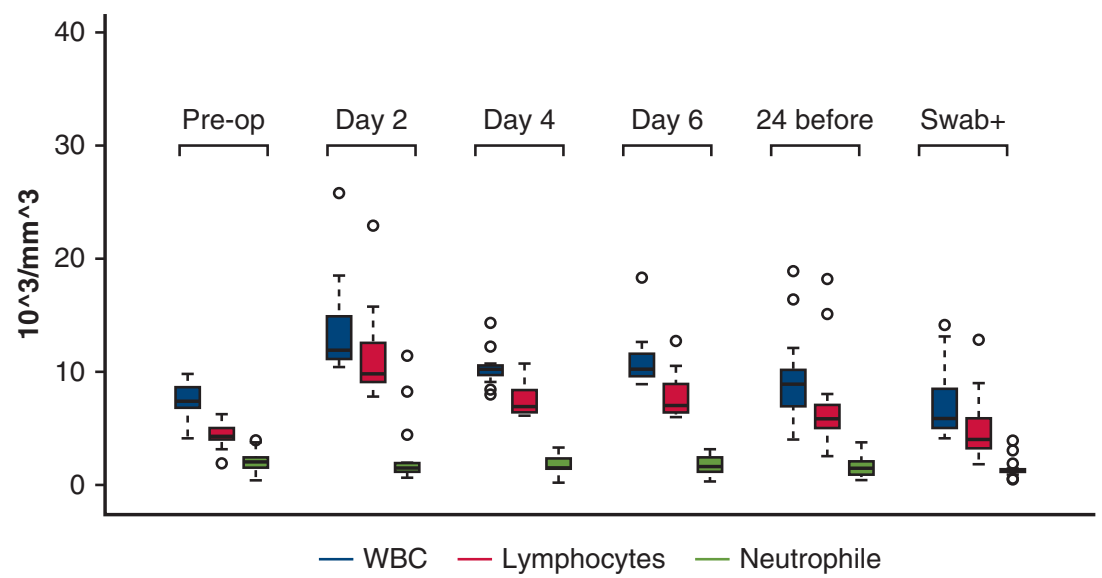

FIGURE 2. WBC, lymphocytes, and neutrophils from baseline (preoperative), day 2, day 4, and day 6 until coronavirus disease 2019 diagnosis. Values are presented with box plots (upper and lower borders of the box represent the upper and lower quartiles; the middle horizontal line represents the median; the upper and lower whiskers represent the maximum and minimum values of non-outliers; extra dots represent outliers) (see Table 4). WBC, White blood cell. 
The dynamic changes of lymphocyte subsets of patients with novel coronavirus disease and their correlation with the disease severity is still under investigation. ${ }^{6,7}$ It has been hypothesized that the degree of lymphopenia (and proinflammatory cytokine storm) is generally greater in patients with severe COVID-19 than in mild cases. ${ }^{7,8}$ Some other evidence suggests that the neutrophil count is also greater in patients with severe COVID-19 disease. ${ }^{6}$

In our series, among the 3 patients who died, a certain degree of preoperative lymphopenia was observed in 2 patients $\left(1.5\right.$ and $1.310^{3} / \mathrm{mm}^{3}$, respectively) and severe in 1 $\left(0.310^{3} / \mathrm{mm}^{3}\right)$. The following full blood count analysis demonstrated a persistent lymphopenia and significantly greater count of neutrophils. However, a greater count of neutrophils could be observed in all positive patients. Following extracorporeal circulation and extracorporeal membrane oxygenation, substantial decreases in the number and function of some populations of lymphocytes are commonplace. $^{9-11}$ Others have reported increases in the number of neutrophils ${ }^{11,12}$ and D-dimer ${ }^{13}$ and reduced antithrombin III levels. ${ }^{13}$ It is also known that extracorporeal circulation may up-regulate interleukin-6. ${ }^{14-16}$ In summary, extracorporeal circulation elicits an important systemic inflammatory response syndrome ${ }^{17,18}$ that may last up to several days after the index surgery. ${ }^{16}$ Therefore, we believe that extracorporeal circulation may act as "confounder" and in some cases may delay the COVID19 diagnosis and can exacerbate the clinical scenario (Figure 3 ). The systemic inflammatory response syndrome state after extracorporeal circulation may in some cases lead to acute respiratory acute respiratory distress syndrome. ${ }^{19}$ Nonetheless, CT of the chest differential diagnosis may be an actual issue in patients affected by COVID-19 after cardiac surgery.

At a consistent but slow pace, the cardiac surgery community is trying worldwide to resume the surgical activity. ${ }^{20}$ It is highly debated whether a second wave of infection with a new pandemic will occur at certain point in the future. Many urgent patients were denied cardiac surgery and cardiac interventions during the first peak of the pandemic also because at that time personal protective equipment and nasopharyngeal swabs facilities were not freely available and accessible. Italy was among one of the first countries to be severely hit by COVID-19; however, an effort was taken to provide, at least in each province, cardiac surgery coverage for urgent and nondeferrable cases. While we were designed as dedicated "COVID-free" cardiac unit and we strictly followed the recommendations issued by the local government (epidemiologic screening, temperature screening, no visitors allowed) and wore personal protective equipment, we could not avoid a SARS-CoV-2 outbreak among patients and health care workers. Intuitively, the recommendations issued by the local Italian authorities were insufficient to protect both patients and the health care worker community, yet they should be set in the context of an unprecedented global shortage of nasopharyngeal swab and also personal protective equipment.

\section{Cardiac surgery outcomes in patients with COVID-19}

\begin{tabular}{|c|c|c|}
\hline Background & Patients & Results \\
\hline $\begin{array}{l}\text { The impact of COVID-19 in } \\
\text { patients referred for } \\
\text { cardiac surgery is } \\
\text { unknown. There are no } \\
\text { firm recommendations } \\
\text { available to guide decision } \\
\text { making for patients } \\
\text { requiring cardiac surgery } \\
\text { during pandemic. }\end{array}$ & $\begin{array}{c}20 \text { patients were found } \\
\text { positive to Sars-CoV-2 } \\
\text { sometimes after urgent } \\
\text { cardiac surgery } \\
\text { (18 open heart surgery, } \\
2 \text { TAVR) }\end{array}$ & $\begin{array}{l}3 \text { patients died; COVID-19 } \\
\text { diagnosis after cardiac } \\
\text { surgery might be difficult } \\
\text { due to the inflammatory } \\
\text { state that follows the CPB. } \\
\text { Complex hospital resources } \\
\text { reorganization is needed to } \\
\text { safely resume surgery. }\end{array}$ \\
\hline
\end{tabular}

FIGURE 3. The impact of SARS-CoV-2 infection in patients referred for urgent cardiac surgery is largely unknown. We experienced a major SARS-CoV-2 outbreak in our cardiac surgery unit, with 18 patients who tested positive early after surgery and 2 after TAVR. Three patients died. COVID-19 diagnosis after cardiac surgery may be difficult due to the systemic inflammatory state that follows the CPB. COVID-19, Coronavirus disease 2019; SARS-CoV-2, severe acute respiratory syndrome coronavirus $2 ; T A V R$, transcatheter aortic valve replacement; $C P B$, cardiopulmonary bypass. 

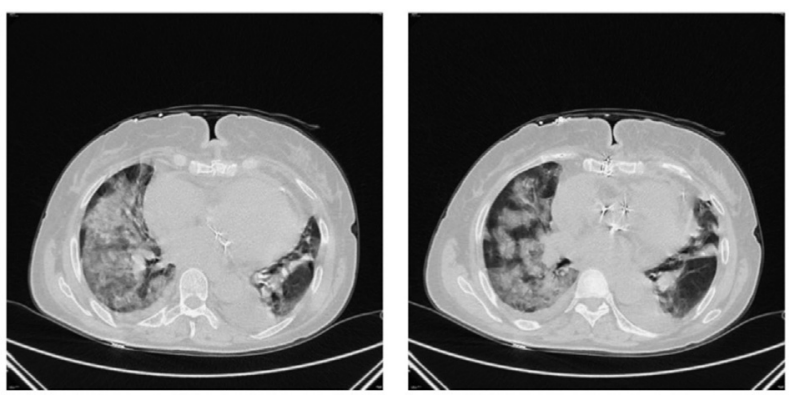

VIDEO 1. The effect of COVID-19 infection in patients undergoing urgent cardiac surgery. Video available at: https://www.jtcvs.org/article/ S0022-5223(20)32872-5/fulltext.

At the moment of the writing of this manuscript, the hospital policy has radically changed. All elective patients are screened with nasopharyngeal swab before admissions in the clinical area with the possibility of having results ready in less than an hour for the semielective or urgent cases. As others, we have created a dedicated area in the hospital (named "gray area" or "bubble") (Figure E1), where patients may stay until the nasopharyngeal swabs are processed. In such areas, face shields and personal protective equipment as such as FFP2/3 (Filtering Face Piece)/N95 masks are mandatory for health care workers. Importantly, this "bubble" area has dedicated resources such as echo and electrocardiography machines and a portable chest radiograph station with no crossover with other clinical areas. The "bubble" has also one "red-room" for urgent cases that may require invasive mechanical ventilation.

A no-visitors policy has been instituted since the beginning of the SARS-CoV-2 peak; "essential visitors" are allowed in to the clinical area if they can provide a negative recent ( $<2$ days) nasopharyngeal swab. All health care workers undergo a nasopharyngeal swab every 2 weeks.

Figure E1 shows the flowchart on how we deal with patients (urgent and elective or semielective) with unknown COVID-19 status along with the "bubble principles."

What we have also learned from our experience is that after cardiac surgery, COVID-19 diagnosis is not always intuitive. Suspicious respiratory disease after cardiac surgery should be immediately investigated with nasopharyngeal swab and, in some circumstances, specimens from the lower respiratory tract might be also tested for SARS-Cov-2 (Table E2).

In the light of a possible new pandemic, we believe that such hospital assets may guarantee a reasonable margin of safety. Our surgical activity (elective/semielective and urgent) resumed on July 2020; since then, following the described screening measures, no further positive cases for SARS-Cov-2 were detected.

There are no firm recommendations available to guide decision making for patients requiring cardiac surgery during pandemic ${ }^{21}$; at this time of crisis, taking in consideration also the possibility of a SARS-Cov-2 surge, it is pivotal to share information and promote cooperation between associations of cardiac surgeons. ${ }^{21}$

This study has limitations. Perhaps the biggest weakness is that we could not determine the date of the exact onset of the infection. Some patients may have been exposed to the virus before surgery, yet it would be more rational to suppose that the majority of them became infected at some stage after the operation. Finally, we did not explore the correlation between severity of COVID-19 symptoms and risk factors for cardiovascular diseases.

\section{CONCLUSIONS}

Here we present a series of patients who underwent complex cardiac surgery and were found positive for the new coronavirus after surgery. We could not determine precisely when they were exposed to the SARS-CoV-2; however, the COVID-19 infection after cardiac surgery, regardless the time of the onset, remains a serious condition. Three patients died.

Extracorporeal circulation itself elicits a systemic inflammatory response state that can exacerbate the clinical picture while making the COVID-19 diagnosis more demanding. With this in mind, a complex reorganization of the hospital resources is required to resume cardiac surgery activity.

\section{Conflict of Interest Statement}

The authors reported no conflicts of interest.

The Journal policy requires editors and reviewers to disclose conflicts of interest and to decline handling or reviewing manuscripts for which they may have a conflict of interest. The editors and reviewers of this article have no conflicts of interest.

\section{References}

1. Haft JW, Atluri P, Alawadi G, Engelman D, Grant MC, Hassan A, et al. Adult cardiac surgery during the COVID-19 pandemic: a tiered patient triage guidance statement. Ann Thorac Surg. 2020;160:452-5.

2. Bonalumi G, di Mauro M, Garatti A, Barili F, Gerosa G, Parolari A, Italian Society for Cardiac Surgery Task Force on COVID-19 Pandemic. The COVID-19 outbreak and its impact on hospitals in Italy: the model of cardiac surgery. Eur J Cardiothorac Surg. 2020;57:1025-8.

3. Fudulu DP, Angelini GD. Cardiac surgery in the time of the coronavirus. J Card Surg. 2020;35:1177-9.

4. Fukuhara S, Rosati CM, El-Dalati S. Acute type A aortic dissection during COVID-19 outbreak. Ann Thorac Surg. 2020;110:e405-7.

5. Rescigno G, Firstenberg M, Rudez I, Uddin M, Nagarajan K, Nikolaidis N. A case of postoperative Covid-19 infection after cardiac surgery: lessons learned. Heart Surg Forum. 2020;23:E231-3.

6. Zheng M, Gao Y, Wang G, Song G, Liu S, Sun D, et al. Functional exhaustion of antiviral lymphocytes in COVID-19 patients. Cell Mol Immunol. 2020;17:533-5.

7. He Z, Zhao C, Dong Q, Zhuang H, Song S, Peng G, et al. Effects of severe acute respiratory syndrome (SARS) coronavirus infection on peripheral blood lymphocytes and their subsets. Int J Infect Dis. 2005;9:323-30.

8. Tan L, Wang Q, Zhang D, Ding J, Huang Q, Tang YQ, et al. Lymphopenia predicts disease severity of COVID-19: a descriptive and predictive study. Signal Transduct Target Ther. 2020;5:33.

9. Henry BM. COVID-19, ECMO, and lymphopenia: a word of caution. Lancet Respir Med. 2020;8:e24. 
10. Biglioli P, Cannata A, Alamanni F, Naliato M, Porqueddu M, Zanobini M, et al. Biological effects of off-pump vs. on-pump coronary artery surgery: focus on inflammation, hemostasis and oxidative stress. Eur J Cardiothorac Surg. 2003; 24:260-9.

11. Hiesmayr MJ, Spittler A, Lassnigg A, Berger R, Laufer G, Kocher A, et al. Alterations in the number of circulating leucocytes, phenotype of monocyte and cytokine production in patients undergoing cardiothoracic surgery. Clin Exp Immunol. 1999;115:315-23.

12. Fosse E, Mollnes TE, Ingvaldsen B. Complement activation during major operations with or without cardiopulmonary bypass. J Thorac Cardiovasc Surg. 1987; 93:860-6.

13. Hunt BJ, Parratt RN, Segal HC, Sheikh S, Kallis P, Yacoub M. Activation of coagulation and fibrinolysis during cardiothoracic operations. Ann Thorac Surg. 1998;65:712-8.

14. Hedman A, Larsson PT, Alam M, Wallen NH, Nordlander R, Samad BA. CRP, IL-6 and endothelin-1 levels in patients undergoing coronary artery bypass grafting. Do preoperative inflammatory parameters predict early graft occlusion and late cardiovascular events? Int J Cardiol. 2007;120: 108-14.

15. Abe K, Nishimura M, Sakakibara T. Interleukin-6 and tumour necrosis factor during cardiopulmonary bypass. Can J Anaesth. 1994;41:876-7.
16. Parolari A, Camera M, Alamanni F, Naliato M, Polvani GL, Agrifoglio M, et al. Systemic inflammation after on-pump and off-pump coronary bypass surgery: a one-month follow-up. Ann Thorac Surg. 2007;84:823-8.

17. Warren OJ, Smith AJ, Alexiou C, Rogers PL, Jawad N, Vincent C, et al. The inflammatory response to cardiopulmonary bypass: part 1-mechanisms of pathogenesis. J Cardiothorac Vasc Anesth. 2009;23:223-31.

18. Kowalewski M, Fina D, Slomka A, Raffa GM, Martucci G, Lo Coco V, et al. COVID-19 and ECMO: the interplay between coagulation and inflammationa narrative review. Crit Care. 2020;24:205.

19. Asimakopoulos G, Smith PL, Ratnatunga CP, Taylor KM. Lung injury and acute respiratory distress syndrome after cardiopulmonary bypass. Ann Thorac Surg. 1999;68:1107-15.

20. Wood DA, Mahmud E, Thourani VH, Sathananthan J, Virani A, Poppas A, et al. Safe reintroduction of cardiovascular services during the COVID-19 pandemic: guidance from North American Societies. Can J Cardiol. 2020;36:971-6.

21. Benedetto U, Goodwin A, Kendall S, Uppal R, Akowuah E. A nationwide survey of UK cardiac surgeons' view on clinical decision making during the COVID-19 pandemic. J Thorac Cardiovasc Surg. 2020;160:968-73.

Key Words: new coronavirus, COVID-19, SARS-CoV-2, cardiac surgery 

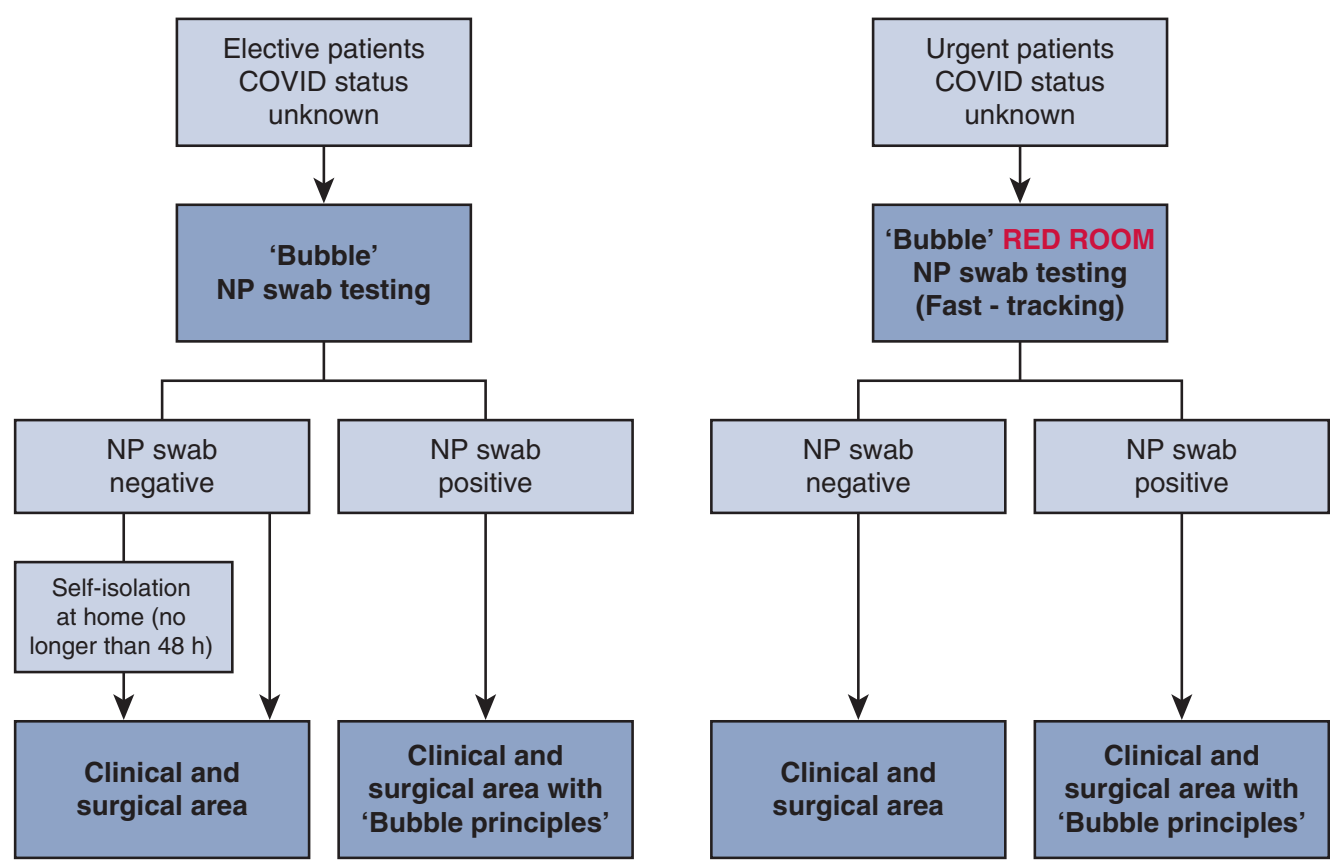

FIGURE E1. Flowchart for assessment of unknown COVID-19 status patients. Before admission to the clinical/surgical area, elective patients are admitted in to the "gray area" or "bubble" and NP swab testing is carried out. In this area, personal protective equipment (FFP [Filtering Face Piece] 2/3 and face shield/eye protection/long-sleeved fluid-repellent gown and gloves) are mandatory for health care workers. If the swab is negative, the patient is admitted onto the ward for further treatment. In the event of a positive swab, the patient must be treated accordingly to the bubble principle: (1) create a bubble around the patient; (2) stay outside the bubble; (3) enter the bubble consciously; (4) stop the bubble from touching the environment; (5) samples leave the bubble in a bubble of their own; and (6) aerosols break the bubble. The gray area is also equipped with ventilator for invasive mechanical ventilation for urgent patients. COVID-19, Coronavirus disease 2019; NP, nasopharyngeal. 
TABLE E1. Patient characteristics after resumed surgical activity following the COVID-19 outbreak

\begin{tabular}{|c|c|}
\hline \multicolumn{2}{|l|}{$\mathbf{N}=\mathbf{1 0 8}$} \\
\hline Age, $y$, mean \pm SD & $71 \pm 11.2$ \\
\hline Male sex, $\mathrm{n}(\%)$ & $40(37)$ \\
\hline Coronary artery bypass grafting, $\mathrm{n}(\%)$ & $31(28.7)$ \\
\hline Aortic valve replacement, $\mathrm{n}(\%)$ & $14(12.9)$ \\
\hline Transcatheter aortic valve replacement, $\mathrm{n}(\%)$ & $16(14.8)$ \\
\hline Mitral valve repair, $\mathrm{n}(\%)$ & $14(12.9)$ \\
\hline Mitral valve replacement, $\mathrm{n}(\%)^{*}$ & $6(5.5)$ \\
\hline $\begin{array}{l}\text { Mitral valve surgery and coronary artery bypass grafting, } \\
\text { n (\%) }\end{array}$ & $8(7.4)$ \\
\hline $\begin{array}{l}\text { Aortic valve replacement and coronary artery bypass } \\
\text { grafting, } \mathrm{n}(\%)\end{array}$ & $3(2.7)$ \\
\hline Aortic valve and ascending aorta replacement, $\mathrm{n}(\%)$ & $3(2.7)$ \\
\hline David/Bentall procedure, $\mathrm{n}(\%)$ & $5(4.6)$ \\
\hline Aortic arch replacement, $\mathrm{n}(\%)$ & $1(0.9)$ \\
\hline Atrial septal defect closure, n (\%) & $3(2.7)$ \\
\hline Aortic valve repair, $\mathrm{n}(\%)$ & $3(2.7)$ \\
\hline Atrial myxoma resection, $\mathrm{n}(\%)$ & $1(0.9)$ \\
\hline EuroSCORE II, median (IQR) & $3.2(4.1)$ \\
\hline Reopening for bleeding, $\mathrm{n}(\%)$ & $2(1.8)$ \\
\hline Need for prolonged intubation, $\mathrm{n}(\%)$ & $3(2.7)$ \\
\hline In-hospital length of stay, d, median (IQR) & $12(5)$ \\
\hline 30-d in-hospital mortality, n (\%) & $2(1.8)$ \\
\hline
\end{tabular}




\section{TABLE E2. Take-home message}

What we learned:

- Testing both patients and health care workers for the new coronavirus with NP swabs it is at the heart of COVID-19 screening and prevention

- Cardiac surgery patients and health care workers can be highly exposed to SARS-CoV-2 infection

- COVID-19 infection at any stage of the cardiac surgery journey, from preoperative to postoperative course, remains a dreadful condition

- Diagnosis may be more difficult after cardiac surgery; the inflammatory state that follows the CPB may mask laboratory findings

What we changed:

- A dedicated area ("gray area" or "bubble area") was created. The "bubble" is a specific environment in which elective or semielective patients are kept isolated until NP swabs are processed; when the patient is cleared, they then are allowed to enter clinical area (see also Video 1)

- Urgent cases transferred from other hospital or A\&E are accepted into the clinical area only if the NP swab is negative. The "bubble" has a "red room" with a mechanical ventilator

- Hospital resources such as echo, ECG, portable CX, and other equipment are specifically allocated to the "bubble"

- Dedicated health care workers must wear FFP2/3/N95 mask, gowns, gloves, and face shield in the bubble area

- Education at all level is promoted with seminars (webinar) on COVID-19

- Strict "bare below elbow policy" in the clinical area

- Every 2 wk health care workers must undergo surveillance NP swab

- Low threshold for CT scan of the chest and NP swab in case of postoperative respiratory failure

$N P$, Nasopharyngeal; COVID-19, coronavirus disease 2019; SARS-CoV-2, severe acute respiratory syndrome coronavirus $2 ; C P B$, cardiopulmonary bypass; $A \& E$, accident/ emergency; $E C G$, electrocardiogram; $C X$, chest x-ray; FFP, Filtering Face Piece; $C T$, computed tomography. 